\title{
Morphometric Analysis of Infraorbital Foramen Using Cone Beam Computed Tomography in a Cohort of Sri Lankan Adults
}

\author{
Análisis Morfométrico del Foramen Infraorbitario Mediante Tomografía \\ Computarizada de Haz Cónico en una Cohorte de Adultos de Sri Lanka
}

\author{
I. P. Thilakumara ${ }^{1}$; P. V. K. S. Hettiarachchi ${ }^{2}$; R. M. Jayasinghe ${ }^{1}$; \\ M. C. N. Fonseka ${ }^{3}$; R. D. Jayasinghe ${ }^{2}$ \& C. D. Nanayakkara ${ }^{4}$
}

\begin{abstract}
THILAKUMARA, I. P.; HETTIARACHCHI, P. V. K. S.; JAYASINGHE, R. M.; FONSEKA, M. C. N.; JAYASINGHE, R. D. \& NANAYAKKARA, C. D. Morphometric analysis of infraorbital foramen using cone beam computed tomography in a cohort of Sri Lankan adults. Int. J. Morphol., 39(2):489-496, 2021.
\end{abstract}

SUMMARY: Infraorbital foramen (IOF) located bilaterally within the maxillary bone about $1 \mathrm{~cm}$ inferior to the infraorbital margin is a vital landmark when delivering local anesthesia and during surgical interventions in the midface region. A total of 122 infraorbital foramina in 61 cone beam computed tomographic (CBCT) images of 32 females and 29 males in the age range of 17 to 32 were analyzed to determine the shape, direction, presence of accessory foramina, size and the precise position of IOF in relation to the inferior orbital margin (IOM), maxillary midline (MM), lateral nasal wall (LNW), alveolus (ALV) and maxillary teeth in a group of Sri Lankan people. The IOF was oval in shape $(80.3 \%$ and $88.5 \%$ on the right and left side, respectively) in a majority of individuals. The infraorbital foramina were located at a mean distance of $5.56 \pm 3.95$ and $4.91 \pm 2.08 \mathrm{~mm}$, below the IOM on the right and left side, 27.13 \pm 2.6 and $26.99 \pm 2.73$ on the right and left side from the mid maxillary line, $11.96 \pm 3.45 \mathrm{~mm}$ and $12.18 \pm 3.35$ from the LNW on the right and left side and $29.59 \pm 3.59$ and $29.65 \pm 3.28$ above the alveolar crest on the right and left side. There were no statistically significant differences between the left and right sides or between sexes. Majority of IOF (37.5\% and 55.9\% on the right and left side, respectively) were located in the vertical plane passing though the maxillary second premolar tooth.

KEY WORDS: Infraorbital foramen; Infraorbital nerve; Morphometry.

\section{INTRODUCTION}

The infraorbital foramen (IOF) is located bilaterally within the maxillary bone about $1 \mathrm{~cm}$ inferior to the infraorbital margin (Standring, 2008). The infraorbital nerve and vessels traverse through this foramen. It is relatively larger than the supraorbital foramen and varies in form and position (Berge \& Bergman, 2001). The infraorbital nerve, the continuation of the maxillary, the second division of the trigeminal nerve, is exclusively a sensory nerve. It traverses the inferior orbital fissure into the inferior orbital canal and emerges on the face at the IOF. It divides into several branches that innervate the skin and the mucous membrane of the midface, such as the lower eyelid, cheek, lateral aspect of the nose, upper lip and the labial gum which are important in oral and maxillofacial surgical practice (Standring).

The IOF is a vital landmark when delivering local anesthesia in carrying out surgical interventions in the midface region. The infraorbital nerve block is often used to accomplish regional anesthesia of the face. Nerve blocks are useful when repair of a large area is needed in an area innervated by one nerve. Further, this procedure offers several advantages over local tissue infiltration. Blockage of a nerve is also useful when local infiltration may not be possible, ineffective or could result in tissue damage or distortion.

An infraorbital nerve block is very useful for procedures which involve the skin between the lower eyelid, upper lip and for dental procedures on the ipsilateral maxillary teeth (Kothari et al., 2019). The direction and position of IOF also determine the acupuncture point used in the treatment of trigeminal neuralgia (Wilkinson, 1999). Infraorbital nerve injuries might occur in the anterior and superior walls during the surgical treatment such as rhinoplasty, Caldwell-Luc surgical procedures, tumor

\footnotetext{
${ }^{1}$ Department of Prosthetic Dentistry, Faculty of Dental Sciences, University of Peradeniya, Sri Lanka.

${ }^{2}$ Department of Oral Medicine and Periodontology, Faculty of Dental Sciences, University of Peradeniya, Sri Lanka.

${ }^{3}$ Department of Restorative Dentistry, Faculty of Dental Sciences, University of Peradeniya, Sri Lanka.

${ }^{4}$ Department of Basic Sciences, Faculty of Dental Sciences, University of Peradeniya,Sri Lanka.
} 
surgery, orbital basis reduction (blow-out), zygomatic region fractures and Le Fort type-I osteotomy (Mozsary \& Middleton, 1983). Therefore, knowing the exact anatomical location is important in order to guarantee safe and successful delivery of regional anesthesia and to evade the risk of iatrogenic injuries. Multiple studies carried out using dry skulls have demonstrated that the dimensions and relative positions of the IOF vary between different populations and sex (Apinhasmit et al., 2006; Boopathi et al., 2010; Elsheikh et al., 2013; Potu et al., 2019). Cone-beam computed tomography (CBCT) has also been considered in previous research to ascertain the same (Dagistan et al., 2017; Bahsi et al., 2019; Sokhn et al., 2019).

Little information is available on the dimensions and relative position of the IOF in the Sri Lankan population, which have been based on studies carried out by using dry human skulls (Ilayperuma et al., 2010; Nanayakkara et al., 2016). However, to the best of our knowledge, no published data was retrieved regarding the dimensions of IOF using CBCT analysis in the Sri Lankan population. Hence the present study was undertaken to ascertain the shape, dimensions and the position of IOF in relation to clinically relevant landmarks, the maxillary midline (MM), infraorbital margin (IOM) lateral nasal wall (LNW), alveolus (ALV) and maxillary teeth and to determine any variation in the position of IOF between the left and right sides and the sex in a sample of Sri Lankan adults using CBCT imaging.

\section{MATERIAL AND METHOD}

A total of $61 \mathrm{CBCT}$ images of patients (32 females and 29 males) in the age range of 17 to 32 years were selected randomly from the records of patients referred to the Division of Oral Medicine and Radiology, Faculty of Dental Sciences University of Peradeniya for routine CBCT imaging. The de-identified digital imaging and communications of medicine (DICOM) files were used for the assessment. Images demonstrating a clear image of the maxilla, devoid of gross malocclusions, craniofacial anomalies and bony pathology were selected for the analysis. In addition, images belonging to patients less than 17 years, images with incomplete clinical records, maxillofacial trauma, craniofacial anomalies such as cleft lip and palate and those who had undergone orthodontic correction of malocclusion were excluded. Ethical clearance for this study was obtained from the Ethics Review Committee of the Faculty of Dental Sciences, University of Peradeniya, prior to commencement of the study. (ERC/FDS/UOP/1/2017/06) Written informed consent had been obtained from the patients to use the images for study purposes prior to carrying out the CBCT scans. The study was carried out conforming the STROBE Guidelines and ethical standards of the 1964 Helsinki Declaration.

The methods described in our previous study (Jayasinghe et al., 2020) were adopted for CBCT image acquisition and interpretation. These images were retrospectively analyzed in coronal, sagittal and axial sections. In the coronal sections, the shape of IOF and its direction in relation to the midline were assessed. The shape of the foramen was categorized as either oval or circular in outline and foramina with oval shape was sub classified as oblique, vertical, and horizontal, considering its direction in relation to midline. Maximum horizontal (medio-lateral) diameter of the IOF (Fig. 1a) and the horizontal distance between right and left IOFs were also assessed (Fig. 1b). Sagittal sections were assessed for the maximum vertical diameter of the IOF and the soft tissue thickness overlying IOF. Further, the presence and number of accessory foramina were assessed in axial sections.

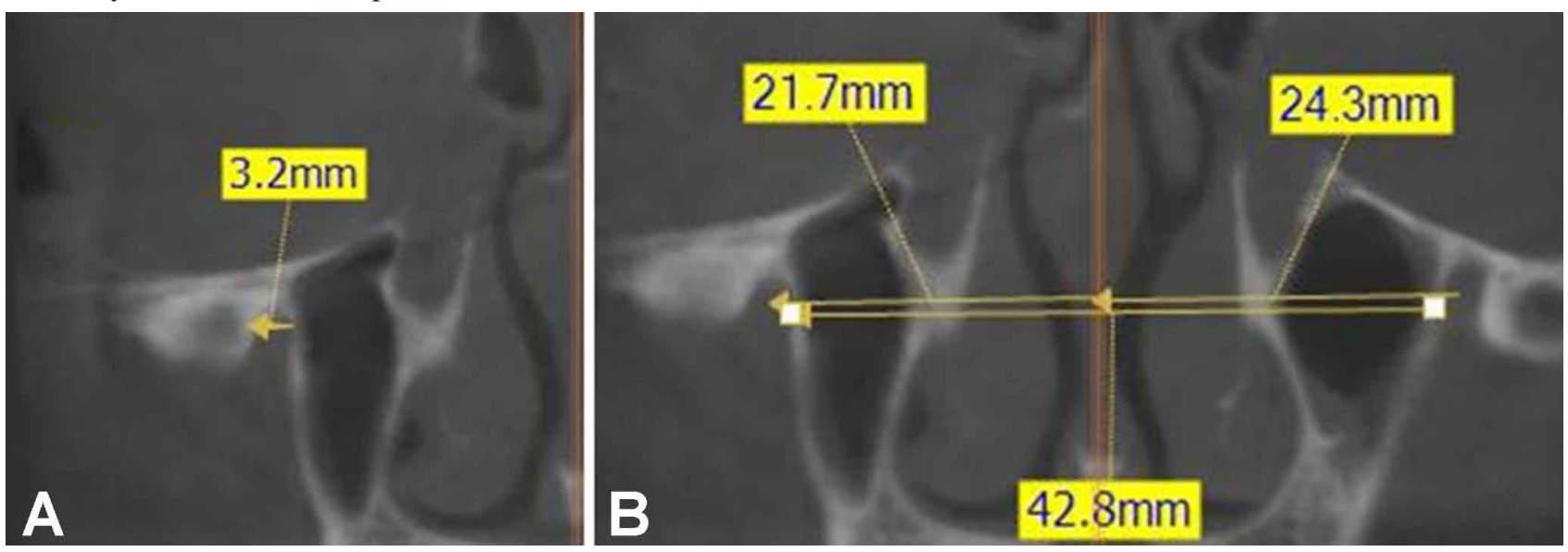

Fig. 1. The coronal section demonstrating (a) Maximum horizontal (Medio-lateral) diameter of the IOF (b) the measurement of distance from right and left infra orbital foramen (IOF) to the mid maxillary line (MML) and the horizontal distance between the right and left infra orbital foramina. 
The position of IOF in relation to important anatomical landmarks were evaluated as:

I. The horizontal distance between the mid maxillary line (MML) and the center of the IOF on each side (Fig. 1b).

II. Horizontal distance from the lateral nasal wall (LNW) to the center of IOF bilaterally (Fig. 2a).

III. Vertical distance from the inferior orbital margin (IOM) to the mid-point of the IOF,

IV. Vertical distance to the crest of the alveolar bone (ALV) from the mid-point of the IOF (Fig. 2b).

$\mathrm{V}$. The tooth that is associated when a vertical line is dropped from the mid-point of the IOF. When assessing this parameter, the relative position of IOF in relation to maxillary teeth was recorded, according to the guide shown in Figure 3 (either as in line with the same vertical axis passing through the long axis of the tooth or in relation to the cusp tips).

Descriptive statistics including the means, standard deviations, minimum and maximum values were computed for each variable, the differences between the left and right sides and males and females were analyzed using the Statistical Package for Social Sciences (SPSS), $20^{\text {th }}$ version. Students' $t$-test was used for the analysis and $P<0.05$ was considered as statistically significant.
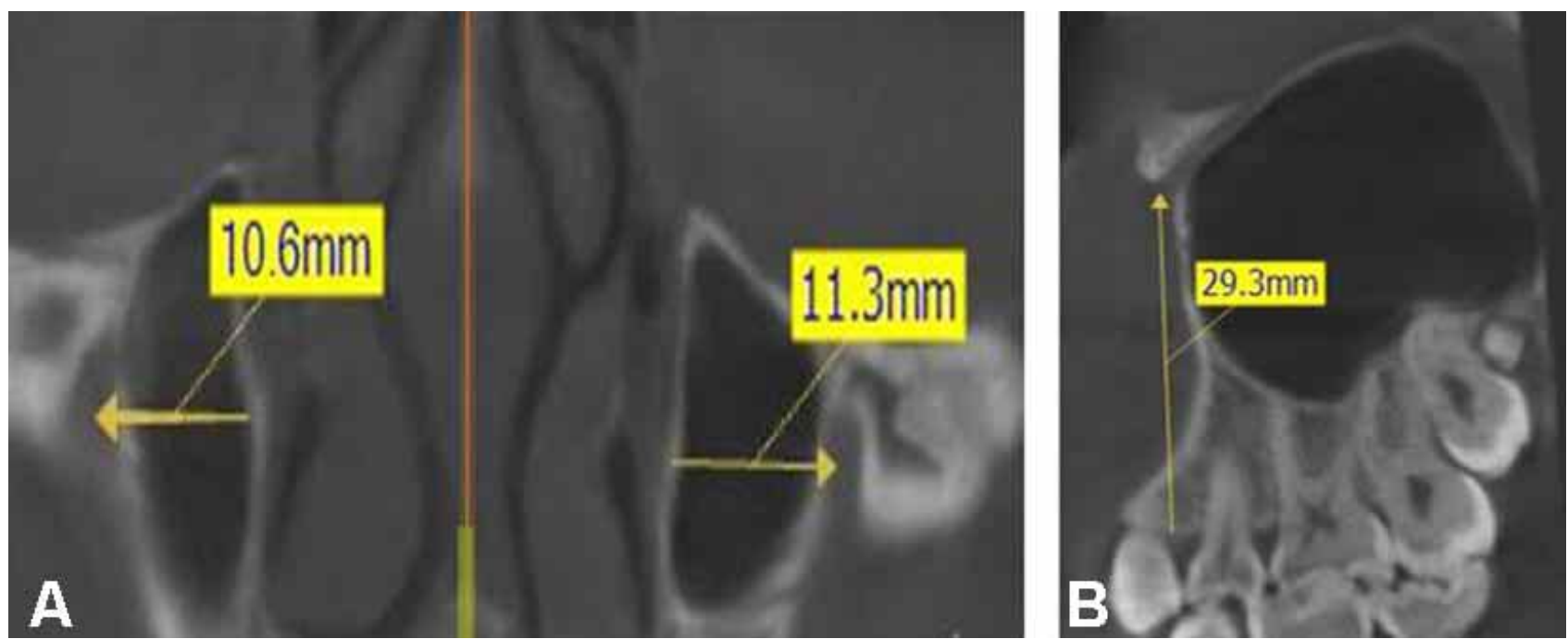

Fig. 2. (a) The coronal section demonstrating horizontal distance from the lateral nasal wall (LNW) to the center of left infra orbital foramen (IOF) bilaterally; (b) the sagittal section demonstrating the vertical distance to the crest of the alveolar bone (ALV) from the mid - point of the IOF.

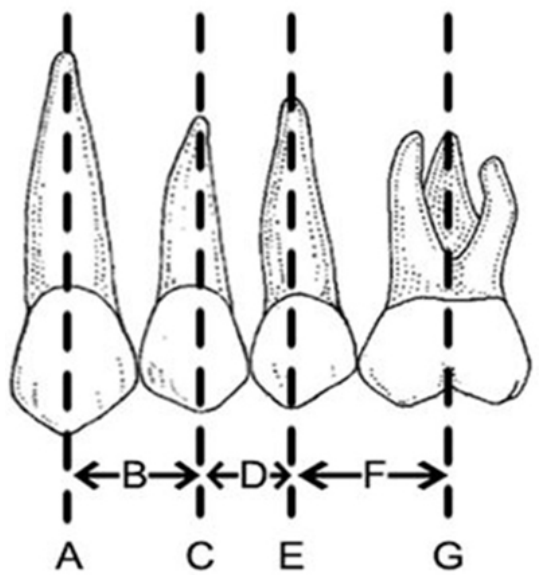

Fig. 3. The midpoint of the infraorbital foramen is in line; along the long axis of the canine (A), between the long axis of the canine and $1^{\text {st }}$ pre molar (B), along the long axis of the first premolar tooth (C), between the long axis of the $1^{\text {st }}$ and the $2^{\text {nd }}$ pre molar (D), along the long axis of the second premolar tooth (E), between the long axis of the $2^{\text {nd }}$ premolar and the molar tooth $(\mathrm{F})$, along the long axis of the first molar tooth $(\mathrm{G})$

\section{RESULTS}

The sample comprised of 122 infraorbital foramina of 32 females and 29 males in the age range of 17 to 32 years. In females on both right and left sides, the predominant shape of the IOF was oval $(87.5 \%)$ followed by the circular shape $(12.5 \%)$. In males, the pattern was similar with $82.8 \%$ having an oval shaped IOF on the right side and $89.7 \%$ on the left side. The difference of having an oval or a circular shaped IOF between females and males was not statistically significant. The difference between the sides was also not statistically significant (Table I).

A majority of females and males had an obliquely directed infraorbital foramen on both left and right sides and the difference between sexes was not statistically significant $(\mathrm{P} \geq 0.001)$. Difference between the sides was also not statistically significant (Table II). 
Table I. Shape of IOF in females and males.

\begin{tabular}{lcccccccc}
\hline Shape & \multicolumn{2}{c}{ Femal es $(\mathrm{N}=32)$} & \multicolumn{2}{c}{ Males $(\mathrm{N}=29)}$. & \multicolumn{2}{c}{ Total sample (N=61) } & P value Sex & P value Side \\
& Left \% & Right $\%$ & Left \% & Right \% & Left \% & Right \% & difference & difference \\
\hline Circle & $12.5 \%(4)$ & $12.5 \%(4)$ & $10.3 \%(3)$ & $17.2 \%(5)$ & $11.5 \%(7)$ & $29.7 \%(9)$ & 0.678 & 0.385 \\
Oval & $87.5 \%(28)$ & $87.5 \%(28)$ & $89.7 \%(26)$ & $82.8 \%(24)$ & $88.5 \%(54)$ & $80.3 \%(52)$ & 0.563 & 0.462 \\
\hline
\end{tabular}

Table II. Direction of IOF in females and males.

\begin{tabular}{|c|c|c|c|c|c|c|c|c|}
\hline \multirow[t]{2}{*}{ Direction } & \multicolumn{2}{|c|}{ Female s $(\mathrm{N}=28)$} & \multicolumn{2}{|c|}{ Males $(\mathrm{N}=26)$} & \multicolumn{2}{|c|}{ Total sample $(\mathrm{N}=54)$} & \multirow{2}{*}{$\begin{array}{l}\mathrm{P} \text { value Sex } \\
\text { difference }\end{array}$} & \multirow{2}{*}{$\begin{array}{l}\text { P value } \\
\text { Side } \\
\text { difference }\end{array}$} \\
\hline & Left $\%$ & Right \% & Left \% & Right \% & Left $\%$ & Right \% & & \\
\hline Horizontal & $10.7 \%(3)$ & $0.7 \%(2)$ & $0 \%(0)$ & $3.8 \%(1)$ & $9.3 \%(5)$ & $1.9 \%(1)$ & - & 0.232 \\
\hline Oblique & $46.4 \%(13)$ & $53.6 \%(15)$ & $69.2 \%(18)$ & $69.2 \%(18)$ & $57.4 \%(31)$ & $61.1 \%(33)$ & 0.212 & 0.456 \\
\hline Vertical & $42.8 \%(12)$ & $39.3 \%(11)$ & $30.8 \%(08)$ & $19.2 \%(5)$ & $37.04 \%(20)$ & $29.6 \%(16)$ & 0.086 & 0.322 \\
\hline
\end{tabular}

All CBCT images demonstrated the presence of a single IOF on both right and left sides. In females $3.1 \%$ showed an accessory foramen on the left side while none were present on the right side. In males $6.9 \%$ showed accessory foramina on the left side while $3.1 \%$ had accessory foramina on the right side. The differences in relation to sex and side were found to be statistically not significant ( $p>0.05$ ) (Table III).

The horizontal and vertical diameters of the IOF and the linear distances from the IOF to the inferior orbital margin, alveolus, maxillary midline and to the lateral wall of nose of both right and left sides are shown in Table IV. According to the analysis, the differences between sexes for each variable were not statistically significant. Further, the differences between left and right sides also were not statistically significant (Table IV).

Majority of IOF on the left side were positioned in relation to a vertical line passing through the second premolar tooth $(31.7 \%)$ followed by a position in relation to a vertical line passing between the first and second premolars. (30 $\%$ ). The pattern was similar on the right side with $35 \%$ of IOF were located in relation to the vertical line passing through the second premolar, and $23.3 \%$ located in relation to the vertical line passing through the first and second premolars. Statistical significance was not considered as the number for each category was smaller than needed for comparison (Table V).

Table III. Presence of accessory foramina on right and left sides of females and males.

\begin{tabular}{|c|c|c|c|c|c|c|c|c|}
\hline \multirow{2}{*}{$\begin{array}{l}\text { Presence of } \\
\text { accessory } \\
\text { foramen }\end{array}$} & \multicolumn{2}{|c|}{ Females $(\mathrm{N}=32)$} & \multicolumn{2}{|c|}{ Males $(\mathrm{N}=29)$} & \multicolumn{2}{|c|}{ Total sample $(\mathrm{N}=61)$} & \multirow{2}{*}{$\begin{array}{l}\mathrm{P} \text { value Sex } \\
\text { difference }\end{array}$} & \multirow{2}{*}{$\begin{array}{c}\mathrm{P} \text { value Side } \\
\text { difference }\end{array}$} \\
\hline & Left $\%$ & Right $\%$ & Left $\%$ & Right \% & Left $\%$ & Right \% & & \\
\hline No & $96.9 \%(31)$ & $100 \%(32)$ & $93.1 \%(27)$ & $96.6 \%(28)$ & $95.1 \%(58)$ & $98.4 \%(60)$ & 0.466 & 0.532 \\
\hline Yes & $3.1 \%(1)$ & $0 \%(0)$ & $6.9 \%(02)$ & $3.4 \%(1)$ & $4.9 \%(3)$ & $1.6 \%(1)$ & - & - \\
\hline
\end{tabular}

Table IV. Measurements of the left and right infraorbital foramina in males and females and total sample (in mm).

\begin{tabular}{|c|c|c|c|c|c|c|c|c|c|}
\hline \multirow[t]{2}{*}{ Mea surement } & \multicolumn{3}{|c|}{ Female } & \multicolumn{3}{|c|}{ Male } & \multirow[t]{2}{*}{ Total sample } & \multirow{2}{*}{$\begin{array}{l}\text { P value } \\
\text { Sex difference }\end{array}$} & \multirow{2}{*}{$\begin{array}{l}\text { P value } \\
\text { Side difference }\end{array}$} \\
\hline & Minimum & Maximum & Mean \pm SD & Minimum & Maximum & Mean \pm SD & & & \\
\hline \multicolumn{10}{|l|}{ Left infraorbital foramen } \\
\hline Maximum vertical diameter & 1.60 & 5.50 & $3.58 \pm 0.85$ & 1.70 & 6.00 & $3.50 \pm 0.95$ & $3.54 \pm 0.99$ & 0.205 & 0.758 \\
\hline Maximum horizontal diameter & 1.90 & 5.40 & $3.17 \pm 0.75$ & 2.21 & 5.1 & $3.28 \pm 0.76$ & $3.22 \pm 0.83$ & 0.247 & 0.786 \\
\hline Distance from IOF to MM & 22.4 & 31.5 & $26.77 \pm 2.4$ & 22.1 & 33 & $27.24 \pm 2.7$ & $26.99 \pm 2.73$ & 0.537 & 0.673 \\
\hline Dis tance from IOF to IOM & 1.05 & 9.5 & $4.63 \pm 2.1$ & 1.1 & 8.5 & $5.2 \pm 1.61$ & $4.91 \pm 2.08$ & 0.616 & 0.512 \\
\hline Dis tance from IOF to LNW & 1.21 & 15.7 & $11.92 \pm 2.89$ & 1.59 & 16.2 & $12.44 \pm 2.74$ & $12.18 \pm 3.35$ & 0.520 & 0.894 \\
\hline Dis tance from IOF to ALV & 24.1 & 34 & $29.46 \pm 2.48$ & 21.2 & 34.8 & $29.85 \pm 3.48$ & $29.65 \pm 3.28$ & 0.528 & 0.839 \\
\hline Soft tissue thickness & 1.54 & 15.9 & $10.98 \pm 3.18$ & 7 & 16.7 & $10.98 \pm 1.73$ & $10.94 \pm 2.89$ & 0.238 & 0.896 \\
\hline \multicolumn{10}{|c|}{ Right infraorbital foramen } \\
\hline Maximum vertical diameter & 1.27 & 4.70 & $3.54 \pm 0.83$ & 1.60 & 5.00 & $3.49 \pm 0.81$ & $3.52 \pm 0.90$ & 0.277 & - \\
\hline Maximum horizontal diameter & 1.88 & 4.6 & $2.98 \pm 0.73$ & 1.88 & 5.1 & $3.24 \pm 0.79$ & $3.11 \pm 0.83$ & 0.271 & - \\
\hline Dis tance from IOF to MM & 22.4 & 30.7 & $26.54 \pm 2.1$ & 22.4 & 34 & $27.73 \pm 2.43$ & $27.13 \pm 2.6$ & 0.477 & - \\
\hline Dis tance from IOF to IOM & 1.37 & 25.3 & $5.45 \pm 4.1$ & 2.31 & 10.4 & $5.67 \pm 1.88$ & $5.56 \pm 3.95$ & 0.495 & - \\
\hline Dis tance from IOF to LNW & 1.23 & 15.9 & $11.52 \pm 2.85$ & 1.65 & 20 & $12.42 \pm 2.74$ & $11.96 \pm 3.45$ & 0.184 & - \\
\hline Dis tance from IOF to ALV & 24.4 & 34.8 & $29.58 \pm 2.94$ & 20 & 34.4 & $29.60 \pm 3.66$ & $29.59 \pm 3.59$ & 0.528 & - \\
\hline Soft tissue thickness & 1.65 & 16.7 & $11.23 \pm 3.16$ & 5.7 & 16.4 & $11.04 \pm 2.26$ & $11.14 \pm 3.08$ & 0.371 & - \\
\hline Dis tance from IOF to IOF & 41.9 & 57.6 & $49.98 \pm 4.03$ & 43.4 & 57.6 & $49.80 \pm 3.07$ & $49.89 \pm 3.89$ & 0.603 & - \\
\hline
\end{tabular}


THILAKUMARA, I. P.; HETTIARACHCHI, P. V. K. S.; JAYASINGHE, R. M.; FONSEKA, M. C. N.; JAYASINGHE, R. D. \& NANAYAKKARA, C. D. Morphometric analysis of infraorbital foramen using cone beam computed tomography in a cohort of Sri Lankan adults. Int. J. Morphol., 39(2):489-496, 2021.

Table V. Position of IOF in relation to maxillary teeth in females and males.

\begin{tabular}{|c|c|c|c|c|c|c|}
\hline \multirow{2}{*}{$\begin{array}{l}\text { Position of IOF in } \\
\text { relation to maxillary teeth }\end{array}$} & \multicolumn{2}{|c|}{ Females $(\mathrm{N}=32)$} & \multicolumn{2}{|c|}{ Males $(\mathrm{N}=28)$} & \multicolumn{2}{|c|}{ Total sample $(\mathrm{N}=60)$} \\
\hline & Left $\%$ & Right \% & Left $\%$ & Right $\%$ & Left $\%$ & Right $\%$ \\
\hline A & $0 \%(0)$ & $0 \%(0)$ & $3.6 \%(1)$ & $3.6 \%(1)$ & $1.7 \%(1)$ & $1.7 \%(1)$ \\
\hline B & $12.5 \%(4)$ & $12.5 \%(4)$ & $14.3 \%(4)$ & $10.8 \%(3)$ & $13.3 \%(8)$ & $11.7 \%(7)$ \\
\hline $\mathrm{C}$ & $18.75 \%(6)$ & $21.9 \%(7)$ & $10.8 \%(3)$ & $14.3 \%(4)$ & $15 \%(9)$ & $18.3 \%(11)$ \\
\hline $\mathrm{D}$ & $28.1 \%(9)$ & $18.75 \%(6)$ & $32.1 \%(9)$ & $28.6 \%(8)$ & $30 \%(18)$ & $23.3 \%(14)$ \\
\hline $\mathrm{E}$ & $28.1 \%(9)$ & $31.2 \%(10)$ & $35.8 \%(10)$ & $39.3 \%(11)$ & $31.7 \%(19)$ & $35 \%(21)$ \\
\hline $\mathrm{F}$ & $9.4 \%(3)$ & $9.4 \%(3)$ & $0 \%(0)$ & $0 \%(0)$ & $5 \%(3)$ & $5 \%(3)$ \\
\hline G & $3.1 \%(1)$ & $3.1 \%(1)$ & $3.6 \%(1)$ & $7.1 \%(2)$ & $3.3 \%(2)$ & $5 \%(3)$ \\
\hline
\end{tabular}

\section{DISCUSSION}

The infraorbital nerve, which emerges through the IOF to appear on the face, is responsible for the sensory innervation to the skin of the malar area between the lower eyelid and the upper lip (Standring). The infraorbital nerve being responsible for the sensory innervation of an apparently larger area, serves as an ideal candidate for a regional nerve block. An injury to the infraorbital nerve might lead to numbness of the upper lip, lateral wall of the nose, lower lid and the infraorbital region of the affected side. Identifying the precise location of the IOF is therefore essential both during surgery involving the midface region and when administering the infraorbital nerve block.

It is widely agreed that the shape of the IOF shows variability (Apinhasmit et al.; Boopathi et al.; Elsheikh et al.; Nanayakkara et al.; Dagistan et al.; Potu et al.). The shape of the IOF was predominantly oval in our sample $(88.5$ $\%$ on the left side and $80.3 \%$ on the right side) followed by the circular type (11.5\% on the left side and $29.7 \%$ ). This is in agreement with the findings of previous studies where the most frequent shape reported was oval (Apinhasmit et al.; Boopathi et al.; Elsheikh et al.; Nanayakkara et al.; Dagistan et al.; Potu et al.). However, in a study by Sokhn et al. in the Lebanese population, the circular shape was the predominant type in females and with regard to sides, the circular shape was more common on the right side. The semilunar and triangular shaped IOFs reported in some previous studies (Apinhasmit et al.; Aggarwal et al., 2015; Nanayakkara et al.; Potu et al.) were not encountered in this study.

The mean vertical and horizontal diameter of the IOF on the right side were $3.52 \pm 0.90$ and $3.11 \pm 0.83$, while those on the left side were $3.50 \pm 0.95$ and $3.28 \pm 0.76$. The average size found in our study was comparable with that observed by Apinhamit et al., (2006) in a Thai population and Varshney \& Sharma (2013) in an Indian population, but smaller than that reported by Aziz et al., (2000) in a study on White, Black and Hispanic skulls.
Studies carried out to identify the precise location of the IOF have made use of various reference points. Bony landmarks such as the IOM, nasion and anterior nasal spine which can be easily palpated are useful to locate the IOF while landmarks such as the lateral margin of the piriform aperture which is neither seen nor clinically palpable may be of limited help to be used for the same. In the present study, clinically relevant landmarks and the positional relationship with the maxillary teeth have been used to determine the location of IOF.

Numerous studies have been carried out with the aim of identifying satisfactory reference points for locating the IOF. The IOM is the widely used reference point to predict the precise location of the IOF (Apinhasmit et al.; Boopathi et al.; Elsheikh et al.; Nanayakkara et al.; Dagistan et al.; Potu et al.). A wide variation has been documented regarding the location of the IOF in relation to the IOM (Table VI). The distance of IOF-IOM has been shown to vary approximately between $4 \mathrm{~mm}$ and over $10 \mathrm{~mm}$ in different population groups (Aziz et al., 2000). The mean distances of the IOF-IOM in the present study, $5.56 \pm 3.95$ and $4.91 \pm$ $2.08 \mathrm{~mm}$ on the right and left sides, respectively, are somewhat lower to those reported in certain other populations (Canan et al., 1999; Apinhasmit et al.; Bahsi et al.). Although the distance from the IOF to the IOM in our study was greater on the right side in both males and females, none of the differences between the sides were statistically significant. Further, the results demonstrate that the distance between IOF-IOM is greater in the males than in females. However, the difference between the sexes was not statistically significant. This is in agreement with the findings of most previous studies but it contradicts with the findings of Apinhasmit et al. where the difference between the IOFIOM of males and females was found to be statistically significant. An IOF situated closer to the IOM as in our study indicates the close proximity of the infraorbital canal to the floor of the orbit. In such a situation, a penetrating globe 
THILAKUMARA, I. P.; HETTIARACHCHI, P. V. K. S.; JAYASINGHE, R. M.; FONSEKA, M. C. N.; JAYASINGHE, R. D. \& NANAYAKKARA, C. D. Morphometric analysis of infraorbital foramen using cone beam computed tomography in a cohort of Sri Lankan adults. Int. J. Morphol., 39(2):489-496, 2021.

injury is a possible complication during an extra oral infraorbital block due to accidental advancement of the needle through the infraorbital canal (Saeedi et al., 2011). This knowledge is vital to clinicians and indicates that extra care should be taken when administering regional nerve block in the infraorbital region to avoid complications.

With regard to the distance from the IOF to LNW and IOF to mid maxillary line, our results showed that the mean distance of the IOF-LNW in the total sample was $11.96 \pm 3.45 \mathrm{~mm}$ on the right side and $12.18 \pm 3.35 \mathrm{~mm}$ on the left side, while the mean distance of IOF-MM was $27.13 \pm 2.6$ and $26.99 \pm 2.73$ on the right and left side, respectively. Although both the measurements of IOF-LNW and IOF-MM were greater in males when compared with those of females and greater on the left side than on the right side, no significant sex or side difference could be observed.

On the other hand, Dagistan et al. conducting a study in a Turkish population using CBCT images reported that although the differences between males and females with regard IOF-LNW measurement were statistically not significant, the differences between the right and left sides were shown to be statistically significant. Contrary to these findings of Dagistan et al., in a study using CBCT images in the Lebanese population Sokhn et al. reported that the values observed for the distance from the IOF to LNW varied significantly between the sexes while the side differences were not significant.

Our results showed that the mean distances from the IOF to mid maxillary line of males $(27.24 \pm 2.7$ and $27.73 \pm 2.43$ on the left and right side respectively) appeared to be greater relative to those of females $(26.77 \pm 2.4$ and $26.54 \pm 2.1$ left and right side, respectively). The similar finding that this distance in males was greater has been previously reported (Apinhasmit et al.; Sokhn et al.). Comparison of the mean distances of the IOF from the mid maxillary line in studies across different population groups showed that this measurement varied approximately between 23 $28 \mathrm{~mm}$. The mean distance recorded in our study was consistent with these values.

Likewise, the mean distance from the IOF to the alveolar crest in the present study was $29.59 \pm 3.59$ and $29.65 \pm 3.28$ on the right and left side respectively. Analyzing dry skulls in an Indian population Aggarwal et al. reported the mean distance of IOF-ALV as $28.41 \pm 62.82 \mathrm{~mm}$. This distance is useful during an intraoral approach to an infraorbital nerve block.

The position of IOF in relation to various anatomical landmarks are variable within the population and among different population groups. Knowing the most accurate position is therefore mandatory to ensure successful regional anesthesia, and to avoid iatrogenic nerve injuries during surgery of the midface region.

The IOF may have an accessory foramen by its side, which may be single or multiple. The occurrence of multiple/ accessory infraorbital foramina (AIOF) is extensively reported in the literature (Apinhasmit et al., 2006; Boopathi et al.; Ilayperuma et al.; Elsheikh et al.; Nanayakkara et al.; Dagistan et al.; Potu et al.; Sokhn et al.). As early as in 1875 Gruber reported that the number of accessory IOF may vary from 1 to 5 (Leo et al., 1995). In a recent study Hwang et al. (2015) analyzing the results published in the literature reported that the occurrence of AIOF varied between $0.8 \%$ and $27.3 \%$. Nanayakkara et al. and Ilayperuma et al. reported that the incidence of AIOF in Sri Lankan dry skulls to be $7.4 \%$ and $3.7 \%$, respectively.

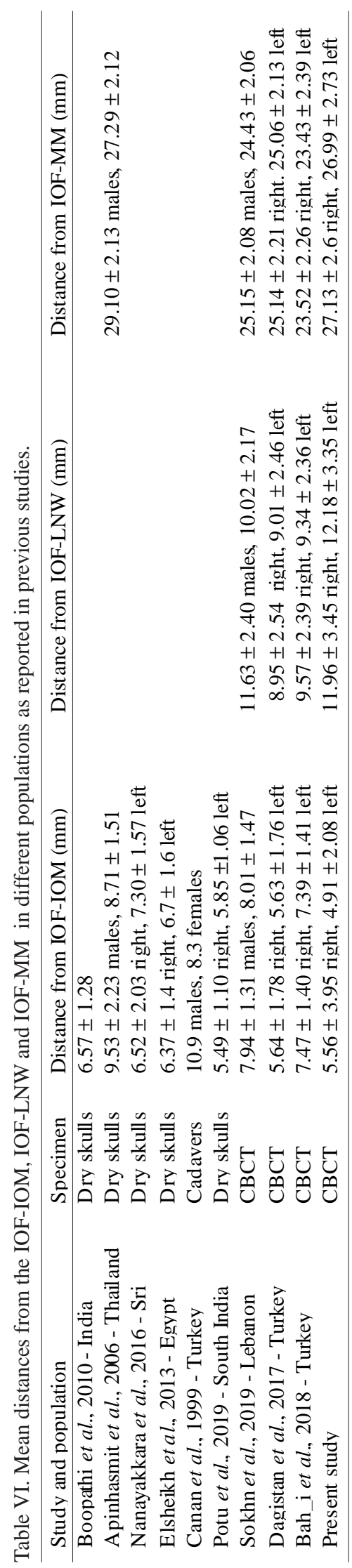


The incidence of accessory foramina in the present study was $4.9 \%$ and $1.6 \%$ on the left and right side, respectively. Although the existence of AIOF was greater on the left side and greater in males, the differences between sides and sexes were found to be statistically not significant. Knowledge regarding the presence of AIOF is an important consideration for the surgeon as it has been reported previously the possibility of having an accessory branch of the infraorbital nerve passing though the AIOF. Previous studies have reported that both the IOF and AIOF were observed to be transmitting their own individual neurovascular bundles (Tubbs et al., 2010; Bahrami et al., 2016). The presence of an AIOF and the accessory branch of the infraorbital nerve raises a mark of caution to both the surgeons and anesthetists as an injury to this branch during surgical maneuvering in the maxillofacial region can result in a sensory deficit and when administering the infraorbital nerve block it may result in insufficient anaesthesia in the region. Double and triple IOF, or accessory foramina were not encountered in the present study, although an occurrence as $2.2-18.2$ and $0.5-1.28 \%$, respectively, has been reported in several previous studies (Leo et al.; Aziz et al., 2000; Apinhasmit et al.; Boopathi et al.; Ilayperuma et al.; Elsheikh et al.; Nanayakkara et al.; Dagistan et al.; Potu et al.; Sokhn et al.).

The results of the present study show that in relation to maxillary teeth, the IOF is frequently located in a vertical plane passing through the maxillary second premolar tooth (31.7 \% and $35 \%$ on the left and right side respectively) followed by a position in a plane passing between the first and second maxillary premolar teeth (30\% and $23.3 \%$ on the left and right side respectively). This observation is in agreement with the findings of previous studies done using dry skulls (Nanayakkara et al.; Aggarwal et al.). However, according to Aziz et al. (2000) the IOF was frequently located in a vertical plane passing through the maxillary 1st premolar tooth. In the present study, the IOF was observed at the maxillary first molar tooth in a small percentage of the sample (3.3\% and $5 \%$ on the left and right side respectively); a situation that is likely to cause an unsuccessful infraorbital nerve block.

\section{CONCLUSION}

The aforesaid description regarding the $\mathrm{IOF}$ demonstrates wide variation in the form, position and the occurrence of accessory foramina among different population groups. Locating accurately the position of the IOF is important to ensure safe and successful regional anesthesia and to avoid iatrogenic injury to the infraorbital nerve during surgery of the midface region. As per the measurements obtained in our study, the IOF is most likely to be located approximately in a position which is about 5 $\mathrm{mm}$ inferior to the infraorbital margin, about $27 \mathrm{~mm}$ lateral to mid maxillary line in a line perpendicular to the mid maxillary line, about $12 \mathrm{~mm}$ lateral to the lateral nasal wall, $29 \mathrm{~mm}$ from the maxillary alveolar crest and in the same vertical plane as the maxillary second premolar tooth. The existence of accessory foramina in a minority of individuals supports the possibility of either a partial or failed infraorbital nerve block or injury to the accessory neurovascular bundle resulting in sensory deficits.

THILAKUMARA, I. P.; HETTIARACHCHI, P. V. K. S.; JAYASINGHE, R. M.; FONSEKA, M. C. N.; JAYASINGHE, R. D. \& NANAYAKKARA, C. D. Análisis morfométrico del foramen infraorbitario mediante tomografía computarizada de haz cónico en una cohorte de adultos de Sri Lanka. Int. J. Morphol., 39(2):489-496, 2021.

RESUMEN: El foramen infraorbitario (FIO) ubicado bilateralmente dentro de la maxila, aproximadamente $1 \mathrm{~cm}$ inferior al margen infraorbitario, es un punto de referencia vital cuando se administra anestesia local y durante intervenciones quirúrgicas en la región media de la cara. Se analizaron un total de 122 forámenes infraorbitarios en 61 imágenes de tomografía computarizada de haz cónico (CBCT) de 32 mujeres y 29 hombres en un rango etario de 17 a 32 años para determinar la forma, dirección, presencia de forámenes accesorios, tamaño y posición precisa de FIO en relación con el margen orbitario inferior (MOI), la línea mediana maxilar (MM), la pared nasal lateral (PNL), el alvéolo (ALV) y los dientes maxilares en un grupo de personas de Sri Lanka. En la mayoría de los adultos se observó que el FIO tenía forma ovalada (80,3 \% y 88,5 \% en el lado derecho e izquierdo, respectivamente) Los forámenes infraorbitarios se ubicaron a una distancia media de 5,56 $\pm 3,95$ y 4,91 $\pm 2,08 \mathrm{~mm}$, por debajo del MOI en los lados derecho e izquierdo; 27,13 $\pm 2,6$ y $26,99 \pm 2,73$ en el lado derecho e izquierdo desde la línea maxilar mediana, $11,96 \pm 3,45 \mathrm{~mm}$ y $12,18 \pm 3,35$ de la PNL en el lado derecho e izquierdo y $29,59 \pm 3,59$ y $29,65 \pm 3,28$ por encima de la cresta alveolar en los lados derecho e izquierdo. No hubo diferencias estadísticamente significativas entre los lados izquierdo y derecho o entre sexos. La mayoría de IOF (37,5 \% y 55,9\% en el lado derecho e izquierdo, respectivamente) se ubicaron en el plano vertical que pasa por el segundo premolar maxilar.

PALABRAS CLAVE: Foramen infraorbitario; Nervio infraorbitario; Morfometría.

\section{REFERENCES}

Aggarwal, A.; Kaur, H.; Gupta, T.; Tubbs, R. S.; Sahni, D.; Batra, Y. K. \& Sondekoppam, R. V. Anatomical study of the infraorbital foramen: A basis for successful infraorbital nerve block. Clin. Anat., 28(6):75360,2015 
Apinhasmit, W.; Chompoopong, S.; Methathrathip, D.; Sansuk, R. \& Phetphunphiphat, W. Supraorbital notch/foramen, infraorbital foramen and mental foramen in Thais: anthropometric measurements and surgical relevance. J. Med. Assoc. Thai., 89(5):675-82, 2006.

Aziz, S. R.; Marchena, J. M. \& Puran, A. Anatomic characteristics of the infraorbital foramen: a cadaver study. J. Oral Maxillofac. Surg., 58(9):992-6, 2000.

Bahrami, A.; Saman, M. \& Ducic, Y. Duplicate infraorbital nerve an uncommon anatomical variation. JSM Oro Facial Surg., 1(1):1001, 2016.

Bahsi, I.; Orhan, M.; Kervancıglu, P. \& Yalçın, E. D. Morphometric evaluation and surgical implications of the infraorbital groove, canal and foramen on cone-beam computed tomography and a review of literature. Folia Morphol. (Warsz.), 78(2):331-43, 2019.

Berge, J. K. \& Bergman, R. A. Variations in size and in symmetry of foramina of the human skull. Clin. Anat., 14(6):406-13, 2001.

Boopathi, S.; Chakravarthy Marx, S.; Dhalapathy, S. L. \& Anupa, S. Anthropometric analysis of the infraorbital foramen in a South Indian population. Singapore Med. J., 51(9):730-5, 2010.

Canan, S.; Asim, O. M.; Okan, B.; Ozek, C. \& Alper, M. Anatomic variations of the infraorbital foramen. Ann. Plast. Surg., 43(6):6137, 1999.

Dagistan, S.; Milolu, O.; Altun, O. \& Umar, E. K. Retrospective morphometric analysis of the infraorbital foramen with cone beam computed tomography. Niger. J. Clin. Pract., 20(9):1053-64, 2017.

Elsheikh, E. M.; Nasr, W. F. \& Ibrahim, A. A. S. Anatomical variations of infraorbital foramen in dry human adult Egyptian skulls, anthropometric measurements and surgical relevance. Otorhinolaryngol. Clin., 5(3):125-9, 2013.

Hwang, K.; Lee, S. J.; Kim, S. Y. \& Hwang, S. W. Frequency of existence, numbers, and location of the accessory infraorbital foramen. $J$. Craniofac. Surg., 26(1):274-6, 2015.

Ilayperuma, I.; Nanayakkara, G. \& Palahepitiya, N. Morphometric analysis of the infraorbital foramen in adult Sri Lankan skulls. Int. J. Morphol., 28(3):777-82, 2010.

Jayasinghe, R. M.; Hettiarachchi, P. V. K. S.; Fonseka, M. C. N.; Nanayakkara, D. \& Jayasighe, R. D. Morphometric analysis of nasopalatine foramen in Sri Lankan population using CBCT. J. Oral Biol. Craniofac. Res., 10(2):238-40, 2020.

Kothari, S. F.; Shimosaka, M.; Iida, T.; Komiyama, O.; Shibutani, K.; Svensson, P. \& Baad-Hansen, L. Quantitative and qualitative assessment of sensory changes induced by local anesthetics block of two different trigeminal nerve branches. Clin. Oral Investig., 23(6):2637-49, 2019.

Leo, J. T.; Cassell, M. D. \& Bergman, R. A. Variation in human infraorbital nerve, canal and foramen. Ann. Anat., 177(1):93-5, 1995.

Mozsary, P. G. \& Middleton, R. A. Microsurgical reconstruction of the infraorbital nerves. J. Oral Maxillofac. Surg., 41(11):697-700, 1983.

Nanayakkara, D.; Peiris, R.; Mannapperuma, N. \& Vadysinghe, A. Morphometric analysis of the infraorbital foramen: the clinical relevance. Anat. Res. Int., 2016:7917343, 2016.

Potu, B. K.; Srungavarapu, G. C. \& Pulakunta, T. Morphometric evaluation of the infraorbital foramen in human dry skulls of South Indian population. Ital. J. Anat. Embryol., 124(3):382-91, 2019.

Saeedi, O. J.; Wang, H. \& Blomquist, P. H. Penetrating globe injury during infraorbital nerve block. Arch. Otolaryngol. Head Neck Surg., 137(4):396-7, 2011.

Sokhn, S.; Challita, R.; Challita A. \& Challita, R. The infraorbital foramen in a sample of the Lebanese population: a radiographic study. Cureus, 11(12):e6381, 2019.

Standring, S. Gray's Anatomy: Anatomical Basis of Clinical Practice. $40^{\text {th }}$ ed. London, Churchill Livingstone Elsevier, 2008.

Tubbs, R. S.; Loukas, M.; May, W. R. \& Cohen-Gadol, A. A. A variation of the infraorbital nerve: its potential clinical consequence especially in the treatment of trigeminal neuralgia: case report. Neurosurgery, 67(3 Suppl. Operative):onsE315, 2010.
Varshney, R. \& Sharma, N. Infraorbital foramen - Morphometric study and clinical application in adult Indian skulls. Saudi J. Health Sci., 2(3):151-5, 2013

Wilkinson, H. A. Trigeminal nerve peripheral branch phenol/glycerol injections for tic douloureux. J. Neurosurg., 90(5):828-32, 1999.

Corresponding author:
Dr. IP Thilakumara

Senior Lecturer

Department of Prosthetic Dentistry,

Faculty of Dental Sciences,

University of Peradeniya

SRI LANKA

Email: ithilakumara@yahoo.com

Received: 02-12-2020

Accepted: 10-01-2021 